\title{
Prevalence and determinants of unintended childbirth in Ethiopia
}

\author{
Yibeltal Tebekaw ${ }^{1 *}$, Bezuhan Aemro ${ }^{2}$ and Charles Teller ${ }^{3}$
}

\begin{abstract}
Background: Ethiopia's population policy specifically aims to reduce TFR from 7.7 to 4.0 and to increase contraceptive use from 4.0\% to 44.0\% between 1990 and 2015. In 2011, the use of contraceptive methods increased seven-fold from $4.0 \%$ to $27 \%$; and the TFR declined by $38 \%$ to 4.8 . The use of modern contraceptives is, however, much higher in the capital Addis Ababa (56\%) and other urban areas but very low in rural areas (23\%) far below the national average (27\%). In 2011, one in four Ethiopian women had an unmet need for contraception. The main aim of this study was to assess the pattern and examine the socioeconomic and demographic correlates of unintended childbirth among women $15-49$ years in Ethiopia.

Methods: Data from the 2011 nationally representative Ethiopia Demographic and Health Survey are used. It covered 16,515 women of which 7,759 had at least one birth and thus included for this study. Multivariate logistic regression is used to see the net effects of each explanatory variable over the outcome variable.

Results: The study found that nearly one in three (32\%) births was unintended; and about two-thirds of these were mistimed. The regression model shows that the burden of unintended births in Ethiopia falls more heavily on young, unmarried, higher wealth, high parity, and ethnic majority women and those with less than secondary education and with large household size. These variables showed statistical significance with the outcome variable.

Conclusion: The study found a relatively high prevalence of unintended childbirth in Ethiopia and this implies high levels of unmet need for child spacing and limiting. There is much need for better targeted family planning programs and strategies to strengthen and improve access to contraceptive services, to raise educational levels, and related information and communication particularly for those affected groups including young, unmarried, multipara, and those with less than secondary level of education. Further quantitative and qualitative research on the consequences of unintended pregnancy and childbirth related to prenatal and perinatal outcomes are vital to document process of change in the problem overtime.
\end{abstract}

Keywords: Women, Unintended pregnancy, Determinants

\section{Background}

Globally an estimated 80 million unintended pregnancies, both mistimed and unwanted, occur each year [1]. Nearly one in every 10 of the pregnancies ends up with unsafe abortions [2]. About $13 \%$ of deaths in 2008 were due to unsafe abortion; $62 \%$ of them were from Africa [1], many from unintended pregnancies that were unsafely aborted [3]. Every year, nearly 6.2 million African (5.5 million from sub Sahara) women have an unsafe abortion; and 29,000 of them die from the procedure

\footnotetext{
* Correspondence: ytebekaw@gmail.com

'World Health Organization, Juba, Republic of South Sudan

Full list of author information is available at the end of the article
}

[1]. Unintended pregnancy and births have grave consequences to the mother and family and are global social and health burdens $[1,4,5]$. Unintended pregnancies mostly arise as a result of nonuse or incorrect use of contraceptives, or a noticeable contraceptive failure $[4,6]$. In 2007, more than one in every five African women of childbearing age had unmet need for family planning. About five percent of the contraceptive users face unexpected pregnancy due to contraceptive failure [1].

In Ethiopia, hundreds die in health facilities each year from abortion-related complications, but many more suffer from injuries or illness related to unsafe procedures [7]. Abortion is legal in Ethiopia since 2005 in 
cases of rape, incest or fetal impairment. In addition, a woman can legally terminate a pregnancy if her life or her child's life is in danger, or if continuing the pregnancy or giving birth endangers her life [8].

Ethiopia's population policy was developed in 1993 just before the UN's International Conference on Population and Development in 1994, which adopted the principle that every pregnancy should be planned and wanted $[9,10]$. The National Population Policy specifically aims to reduce TFR from 7.7 to 4.0 and to increase contraceptive use from $4.0 \%$ to $44.0 \%$ between 1990 and 2015 . According to the 2011 EDHS report, the use of contraceptive methods increased sevenfold in two decades from $4.0 \%$ to $27 \%$; and the TFR declined by $38 \%$ from 7.7 to 4.8 between 1990 and 2011. Modern method use in rural areas was very low (23\%) far below the national average. The level of modern contraceptive use in Ethiopia is encouraging news for improving the health of women and their families. However, it is impossible to meet women's fertility or reproductive goals with existing large number of mistimed or unwanted pregnancies. The country is generally characterized by high fertility, low contraceptive use, high maternal mortality (673 deaths per 100,000 live births) and high unmet need for family planning services [11].

In Ethiopia, the percentage of births that were unwanted or unplanned at the time of conception was $37 \%, 35 \%$ and $28 \%$ in the 2000, 2005, and 2011 respectively [11]. A cross-sectional study from Eastern Ethiopia shows that $33.3 \%$ of sexually active women had their most recent pregnancies classified unintended and the prevalence of unintended childbirth was $14.4 \%$ [12]. Another study from the same region shows a $27.9 \%$ unintended pregnancy level [13]. A nationwide facility based study shows $42 \%$ unintended pregnancies [14]. The studies indicate that younger, unmarried, and multipara women and those among the poor wealth quintiles have higher experience of unintended pregnancies $[13,15]$.

Previous studies in Ethiopia focused on unintended pregnancies not on unintended childbirths and have relied largely on low-scale or localized facility and communitybased surveys $[13,15]$. Little is therefore known about the determinants of unintended childbirth from diverse socioeconomic and demographic contexts at national level. The current study compares women who had unintended births with all other women with history of childbirth. It intends to help policymakers and program designers in Ethiopia understand the extent and correlates of unintended childbirths as such evidence is an essential part in improving the reproductive health service delivery to the needy. The main aim of this study was to assess the pattern and examine the socioeconomic and demographic correlates of unintended childbirth among women 15-49 years in Ethiopia.

\section{Methods}

The data for this paper were drawn from the 2011 nationally representative Ethiopia Demographic and Health Survey (EDHS). This is a secondary analysis of data. Authorization was obtained from the ICF International to download data from the Demographic and Health surveys (DHS) on-line archive and analyze and present findings. The survey was implemented by the Ethiopian Central Statistical Agency (CSA) with the technical assistance of ICF International through the MEASURE DHS project. The survey enquires about household members' and individual characteristics using Household Questionnaire, Woman's Questionnaire and Man's Questionnaire. Individual women of reproductive age (15-49 years) were interviewed face to face on their background characteristics as well as on fertility and family planning behaviour, child mortality, adult and maternal mortality, nutritional status of women and children, the utilization of maternal and child health services, knowledge of HIV/AIDS and prevalence of HIV/AIDS and anaemia [11].

The sample was weighted to make the survey base more accurately representative of the population from which the sample was taken. Thus the descriptive analyses for this paper were based on weighted figures. However, since the multivariate analyses preserve the one respondent-one-response relationship, data were not weighted. The present analysis is restricted to last born children in the five years preceding the survey. EDHS tries to assess the level of unwanted fertility among women age 15-49 through a series of survey questions asked about each of the children born to them in the preceding five years (including current pregnancy). Women were asked about their last birth whether they wanted it then, wanted later, or did not want to have any more children at all. The term "wanted" permits identifying those mistimed pregnancies or births that occurred sooner than desired. In this study, if the birth or pregnancy was wanted then, it was considered to be intended; if it was wanted but at a later time, it was considered to be mistimed, and if it was not wanted at the time of conception, it was considered to be unwanted [11]. The dependent variable of interest in this study is therefore measured as a two-outcome variable and coded as intended birth, if the last childbirth occurred at a time when the woman wanted it, and unintended birth, if the pregnancy or last childbirth occurred at a time when the woman would have wanted it later or did not want it at all. Hence, unintended birth is estimated as the proportion of births resulting from unintended pregnancies.

Both bivariate and multivariate analyses were done to determine the presence of statistically significant associations and strength of associations between explanatory variables and the dependent variable. For this study, p-value of 0.05 
was considered as significant level. The multivariate models (adjusted odds ratio) included variables that were significantly associated with the dependent variable ( $p$-value $<0.05)$ in the bivariate analyses or crude odds ratios. The Hosmer and Lemeshow goodness of fit test showed P-value of 0.89 and Nagelkerke R Square value was 0.63 for the final model which shows that our data fairly fits with the logistic regression model. Multicollinearities were also checked among selected variables including age versus parity, educational status versus working status, and educational status versus wealth index. The Variance Inflation Factor (VIF) and adjusted $\mathrm{R}^{2}$ values for each of the pairs ranged from 1.01- 1.31 and 0.001-0.011 respectively. Commonly, a VIF of 10 and above or a Tolerance $\left(1-R^{2}\right)$ of close to zero would be a concern for multi-collinearity.

A wide range of predictor variables were considered in this study including woman's educational level (no education, primary, and secondary or higher education), working status (whether the woman was working at the time of data collection for remuneration), age (years), marital status (never in union/married, currently married, formerly married), parity (children ever born), wealth index (poor, middle, rich), religion (Orthodox Christian, Muslim, Catholic, Protestant, and Traditional), ethnicity (Tigraway, Oromo, Amhara, Guragie, Somalie, Afar, etc.), history of abortion, woman's decision-making autonomy, and exposure to media. Exposure to media was categorized as adequate if the woman reads newspaper/ magazine or listens radio or watches television at least once a week; inadequate if the woman reads newspaper/ magazine, listens radio or watches television less than once a week. In the 2011 EDHS questions were asked on women's participation in specific household decisions including on spending respondent's earnings, household purchases, visits to family and respondent's healthcare. The decision-making autonomy of women at household level was also considered among the independent variables including decision on own healthcare, large household purchases and visits to relatives. However, we couldn't include them in the final model due to large missing or invalid values of up to $15 \%$ of the sample size.

Other variables treated related to antenatal care, fertility and contraception include history of abortion, current contraceptive use, and knowledge of any contraceptive method. Type of place of residence was used as a control variable.

\section{Results}

The total number of women who had at least one birth and included for this study was 7,759 (weighted $=7905$ ). About $85 \%$ of women were from rural areas, majority of the women (69\%) were aged 20-34 years while two-thirds had no education. About $91 \%$ of the women were currently married and slightly more than half of the households (51\%) had between 4 and 6 persons while $37 \%$ of the women were of parity 3-5. Regarding ethnicity, Oromo women were the majority (35\%); and Orthodox Christians constitute more than $42 \%$ of the respondents.

\section{Prevalence of unintended childbirth}

About 32\% of the 7905 women had an unintended pregnancy. While $21 \%$ were mistimed or were not wanted at the time of conception but later, and $11 \%$ were completely unwanted i.e., wanted to stop childbearing (Figure 1).

Table 1 shows the prevalence of unintended childbirth by the socio-demographic characteristics of the respondents who ever had birth and who reported whether their last child was wanted or unwanted.

Women aged 35-49 years had the highest prevalence of unintended childbirth (37\%); while it was least among women aged $15-19$ at $34 \%(\mathrm{P}<0.001)$. About $86 \%$ of never-married women reported having had unintended pregnancy compared to $31 \%$ and $37 \%$ of currently married/cohabiting and formerly married women, respectively $(\mathrm{P}<0.001)$. Women with parity of two or less had the lowest prevalence of unintended births (28\%) compared to 37\% among those of parity six and above. Women with household $(\mathrm{HH})$ size of seven and above persons experienced the highest prevalence of unintended births at $38 \%(\mathrm{P}<0.001)$.

Women with primary education had higher prevalence of unintended pregnancy (more than 34\%) followed by

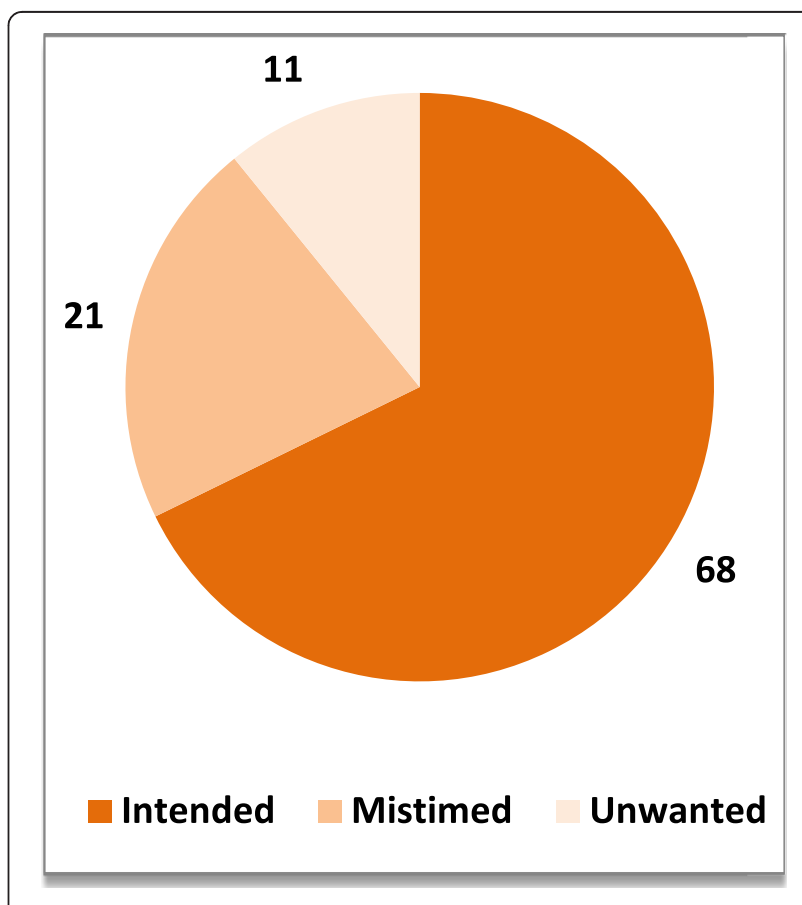

Figure 1 Prevalence of unintended childbirths in Ethiopia. 
Table 1 Prevalence of unintended childbirth by socio-demographic characteristics of women 15-49 years, Ethiopia-2011

\begin{tabular}{|c|c|c|c|c|c|c|c|c|c|}
\hline Characteristics & $\begin{array}{l}\text { Wanted } \\
\text { birth }\end{array}$ & $\begin{array}{l}\text { Unwanted } \\
\text { birth }\end{array}$ & Total & N (weighted) & Tigrie & 80.5 & 19.5 & 100.0 & 524 \\
\hline Age & $P<0.001$ & & & & Others & 72.1 & 27.9 & 100.0 & 2060 \\
\hline $15-19$ & 66.3 & 33.7 & 100.0 & 401 & \multirow{2}{*}{$\begin{array}{l}\text { Knowledge of } \\
\text { contraceptive } \\
\text { method }\end{array}$} & \multirow[t]{2}{*}{$P<0.001$} & & & \\
\hline $20-34$ & 69.4 & 30.6 & 100.0 & 5480 & & & & & \\
\hline $35-49$ & 63.5 & 36.5 & 100.0 & 2024 & Knows no method & 86.0 & 14.0 & 100.0 & 420 \\
\hline Educational level & $P=0.03$ & & & & Knows at least one & 67.3 & 32.7 & 100.0 & 7339 \\
\hline No education & 68.5 & 31.5 & 100.0 & 5268 & \multirow{2}{*}{ Contraceptive use } & \multirow{2}{*}{$P<0.001$} & & & \\
\hline Primary education & 65.6 & 34.4 & 100.0 & 2270 & & & & & \\
\hline Secondary education & 69.6 & 30.4 & 100.0 & 368 & Yes & 61.5 & 38.5 & 100.0 & 1810 \\
\hline \multirow{2}{*}{$\begin{array}{l}\text { Type of place of } \\
\text { residence }\end{array}$} & \multirow[t]{2}{*}{$P=0.305$} & & & & No & 70.1 & 29.9 & 100.0 & 5949 \\
\hline & & & & & Media exposure & $P=0.001$ & & & \\
\hline Urban & 66.5 & 33.5 & 100.0 & 1187 & Inadequate & 69.1 & 30.9 & 100.0 & 5062 \\
\hline Rural & 68.0 & 32.0 & 100.0 & 6717 & Adequate & 65.5 & 34.5 & 100.0 & 2680 \\
\hline \multirow{2}{*}{$\begin{array}{l}\text { Respondent currently } \\
\text { working }\end{array}$} & \multirow[t]{2}{*}{$P<0.001$} & & & & History of abortion & \multicolumn{2}{|l|}{$P=0.024$} & & \\
\hline & & & & & Yes & 67.3 & 32.7 & 100.0 & 6953 \\
\hline No & 70.3 & 29.7 & 100.0 & 5131 & No & 71.2 & 28.8 & 100.0 & 803 \\
\hline Yes & 63.0 & 37.0 & 100.0 & 2768 & Total & 67.8 & 32.2 & 100.0 & 7905 \\
\hline
\end{tabular}

Table 1 Prevalence of unintended childbirth by socio-demographic characteristics of women 15-49 years, Ethiopia-2011 (Continued)
Middle

Rich

Parity

$0-2$

3-5

6 and above

Household size

$1-3$

4-6

7 and above

Religion

Orthodox

Protestant

Muslim

Catholic/Traditional/ others

\section{Marital status}

Never in union

Married/cohabiting

Formerly married

Ethnicity

Afar

Amhara

Oromo

Somalie

\begin{tabular}{|c|c|c|c|}
\hline 70.7 & 29.3 & 100.0 & 3433 \\
\hline 66.4 & 33.6 & 100.0 & 1628 \\
\hline 64.9 & 35.1 & 100.0 & 2844 \\
\hline \multicolumn{4}{|c|}{$P<0.001$} \\
\hline 72.3 & 27.7 & 100.0 & 2751 \\
\hline 66.9 & 33.1 & 100.0 & 2924 \\
\hline 63.3 & 36.7 & 100.0 & 2200 \\
\hline \multicolumn{4}{|c|}{$P<0.001$} \\
\hline 76.3 & 23.7 & 100.0 & 1080 \\
\hline 69.7 & 30.3 & 100.0 & 4056 \\
\hline 61.6 & 38.4 & 100.0 & 2770 \\
\hline \multicolumn{4}{|c|}{$P<0.001$} \\
\hline 64.8 & 35.2 & 100.0 & 3327 \\
\hline 68.3 & 31.7 & 100.0 & 1763 \\
\hline 71.0 & 29.0 & 100.0 & 2563 \\
\hline 69.6 & 30.4 & 100.0 & 247 \\
\hline \multicolumn{4}{|c|}{$P<0.001$} \\
\hline 13.9 & 86.1 & 100.0 & 72 \\
\hline 68.7 & 31.3 & 100.0 & 7185 \\
\hline 62.7 & 37.3 & 100.0 & 649 \\
\hline \multicolumn{4}{|c|}{$P<0.001$} \\
\hline 95.2 & 4.8 & 100.0 & 63 \\
\hline 65.4 & 34.6 & 100.0 & 2256 \\
\hline 61.6 & 38.4 & 100.0 & 2765 \\
\hline 95.9 & 4.1 & 100.0 & 193 \\
\hline
\end{tabular}

those uneducated $(32 \%) \quad(\mathrm{P}<0.001)$. The prevalence of unintended birth was higher among women of the richer households (wealth index) at $37 \%$ followed by the middle wealth quintiles (34\%). There was no statistically significant variation in the prevalence of unintended birth with regards to the woman's type place of residence.

Ethnically, Oromo and Amhara women had the highest prevalence of unintended pregnancy at more than $38 \%$ and $35 \%$ respectively. Muslim women had the lowest unintended childbirth (29\%) compared to Orthodox Christians $(35 \%)$ and Protestants $(32 \%)(\mathrm{P}<0.001)$.

The researchers analysed the association between history of abortion, and knowledge and use of contraception and unintended childbirth. The prevalence of unintended child birth was more than double among those women who know at least one method of contraceptive (32.7\%) compared to those who know no method (14.0\%) (P= 0.000). Similarly, unintended childbirth was higher among those women who use contraceptives $(38.5 \%)(\mathrm{P}=0.000)$; and those who had adequate exposure to media (34.5\%) $(P=0.001)$. The prevalence of unintended childbirth was lower among women with no history of abortion (26.1\%) compared to those with history of abortion (23.2\%) $(\mathrm{P}=0.074)$.

With regards to region of residence (Figure 2), the highest unintended birth rates in 2011 were found in Oromiya Region (38\% aged 15-49), Harari (35\%), Amhara (34\%), and Gambella and Addis Ababa each at $33 \%$. The lowest unintended pregnancy rates were found in Somali $(8 \%)$ and Afar $(9 \%)$ regions $(\mathrm{P}<0.001)$. 


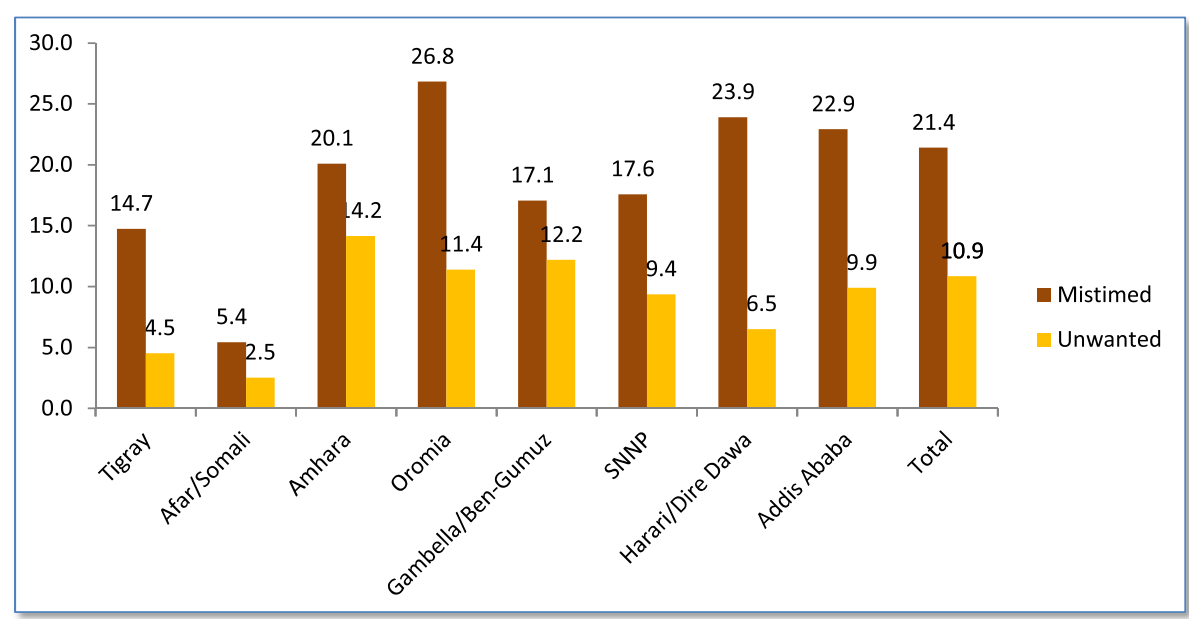

Figure 2 Proportion of unintended births by region of residence, Ethiopia, 2011.

\section{Socio-economic and demographic determinants of} unintended childbirth

In this paper, multivariate logistic regression was run to see the net effects of independent variables over the dependent one. The results of the analysis of the determinants of unintended childbirth are presented in three models (Table 2). Model-I fitted the outcome variable and the socioeconomic variables for urban areas, ModelII for rural and Model-III for both urban and rural combined. Only the geographic, socioeconomic, demographic and other variables, except type of place of residence, which showed statistically significant association in the unadjusted regression models or chi-square tests, were included in the final models. The place of residence did not show any significant association even in the bivariate (chi-square test) analysis (Table 1) but it was included in the final model as a control variable.

Model-I shows that urban women with secondary and above education, married/cohabiting and formerly married (divorced or widowed) women, ethnic Afars, Tigraways, Somalies and Amharas, conctraceptive nonusers were less likely to experience unintended childbirth. On the contrary, women in the rich wealth quintile, and women with 3-5 and 6+ children ever born were more likely to have unintended event. The rural model (Model-II) shows that younger women, the rich, those currently working, women with parity of $6+$, those with household size of $7+$ were more likely to have unintended childbirth; while married or cohabiting women, the Amharas, Somalis and Tigraways, and non-contraceptive users were less likely to experience unintended childbirth.

Model-III (Table 2) shows that teenagers (15-19) were nearly two times more likely to have unintended childbirth compared to those aged 20-34 years. Women with secondary education were $37 \%$ less likely to have unintended births compared to those with no education; while those in the rich wealth quintile households were 1.3 times more likely to have unintended childbirth. Married or cohabiting women and formerly married women had lower odds of having unintended child birth by about $88 \%$ and $80 \%$ compared to the never-in-union women. While considering parity, women of 3-5 and 6 and above parity were 1.3 and 1.6 times more likely to experience unintended childbirth compared to the $0-2$ parity counterparts. The likelihood of experiencing unintended childbirth was low among Protestants and Muslims with each being $24 \%$ and $23 \%$ respectively less likely than Orthodox Christians. With regards to ethnic affiliation, Afars, Amharas, Somalis and Tigraways were $34 \%, 85 \%, 77 \%$ and $63 \%$ less likely to experience unintended child birth compared to the Oromos, the largest ethnic group in Ethiopia.

In this model, women's knowledge of any contraceptive method and history of contraceptive use showed significant association with unintended childbirth. Hence, women who know at least one type of contraceptive method and current users of contraceptives were more likely to have unintended childbirth. History of abortion did not maintain its effect on the final model.

\section{Discussion}

Individuals and couples in Ethiopia want to plan the timing and spacing of their childbearing and to avoid unwanted pregnancies or childbirths for social and economic reasons [11]. Our study shows that in 2011 almost one in three childbirths was unintended of which nearly two-third was mistimed with a similar pattern from other countries including Kenya and Tanzania $[14,16,17]$. At least $27 \%$ of last childbirths in every eight out of 11 regional states and city administrations in Ethiopia were unintended. The national unintended childbirth rate is comparable to other African countries. It is 
Table 2 Binary logistic regression (odds ratio) of unwanted childbirth among women 15-49 years, Ethiopia-2011

\begin{tabular}{|c|c|c|c|}
\hline \multirow[t]{2}{*}{ Variables } & \multirow{2}{*}{$\begin{array}{l}\text { Model-I } \\
\text { AOR [95.0\% C.I.] }\end{array}$} & \multirow{2}{*}{$\begin{array}{l}\text { Model-II } \\
\text { AOR [95.0\% C.I.] }\end{array}$} & \multirow{2}{*}{$\begin{array}{l}\text { Model-III } \\
\text { AOR [95.0\% C.I.] }\end{array}$} \\
\hline & & & \\
\hline \multicolumn{4}{|l|}{ Age $(R C=20-34)$} \\
\hline $15-19$ & $1.53[0.72,3.25]$ & $1.68[1.25,2.25]^{* *}$ & $1.66[1.27,2.17]^{* * * *}$ \\
\hline $35-49$ & $1.03[0.70,1.53]$ & $0.95[0.79,1.14]$ & $0.95[0.80,1.12]$ \\
\hline \multicolumn{4}{|c|}{ Woman's educational level ( $R C=$ No education) } \\
\hline Primary education & $0.97[0.70,1.35]$ & $1.17[1.00,1.37]$ & $1.13[0.99,1.31]$ \\
\hline Secondary education & $0.50[0.33,0.76]^{* *}$ & $1.19[0.69,2.04]$ & $0.63[0.47,0.84]^{* *}$ \\
\hline \multicolumn{4}{|c|}{ Type of place of residence $(R C=$ Urban $)$} \\
\hline Rural & & & $1.10[0.91,1.33]$ \\
\hline \multicolumn{4}{|l|}{ Currently working $(R C=$ No $)$} \\
\hline Yes & $1.08[0.82,1.41]$ & $1.29[1.12,1.49]^{* * * *}$ & $1.23[1.09,1.40]^{* *}$ \\
\hline \multicolumn{4}{|l|}{ Wealth index $(R C=$ Middle) } \\
\hline Poor & $3.61[0.81,16.04]$ & $1.15[0.98,1.36]$ & $1.17[1.00,1.38]$ \\
\hline Rich & $3.11[1.32,7.32]^{*}$ & $1.24[1.05,1.46]^{*}$ & $1.29[1.10,1.51]^{* *}$ \\
\hline \multicolumn{4}{|l|}{ Parity $(R C=0-2)$} \\
\hline $3-5$ & $1.54[1.09,2.18]^{*}$ & $1.21[1.00,1.46]^{*}$ & $1.29[1.09,1.52]^{* *}$ \\
\hline 6 and above & $2.56[1.43,4.57]^{* *}$ & $1.43[1.13,1.83]^{* *}$ & $1.56[1.25,1.94]^{* * * *}$ \\
\hline \multicolumn{4}{|l|}{ Household size $(R C=1-3)$} \\
\hline $4-6$ & $0.99[0.70,1.40]$ & $1.48[1.15,1.89]^{* *}$ & $1.27[1.04,1.55]^{*}$ \\
\hline 7 and above & $1.17[0.73,1.86]$ & $2.06[1.57,2.70]^{* * * *}$ & $1.74[1.39,2.18]^{* * * *}$ \\
\hline \multicolumn{4}{|l|}{ Religion $(R C=$ Orthodo $x)$} \\
\hline Protestant & $0.99[0.63,1.55]$ & $0.73[0.58,0.93]^{* *}$ & $0.76[0.62,0.93]^{* *}$ \\
\hline Muslim & $0.75[0.54,1.05]$ & $0.73[0.60,0.89]^{* *}$ & $0.77[0.65,0.91] * *$ \\
\hline Catholic/Traditional/others & $1.31[0.37,4.64]$ & $0.86[0.59,1.27]$ & $0.90[0.63,1.29]$ \\
\hline \multicolumn{4}{|c|}{ Marital status $(R C=$ Never in union) } \\
\hline Married/cohabiting & $0.07[0.03,0.18]^{* *}$ & $0.18[0.08,0.37]^{* *}$ & $0.12[0.07,0.22]^{* * *}$ \\
\hline Formerly married & $0.17[0.06,0.45]$ & $0.25[0.12,0.53]^{* * *}$ & $0.20[0.11,0.36]^{* * *}$ \\
\hline \multicolumn{4}{|l|}{ Ethnicity $(R C=$ Oromo $)$} \\
\hline Afar & $0.83[0.58,1.18]$ & $0.75[0.60,0.93]^{* *}$ & $0.76[0.63,0.91]^{* *}$ \\
\hline Amhara & $0.11[0.03,0.50]^{* *}$ & $0.15[0.10,0.23]^{* * * *}$ & $0.15[0.10,0.23]^{* * * *}$ \\
\hline Somali & $0.19[0.09,0.40]^{* * * *}$ & $0.11[0.07,0.18]^{* * * *}$ & $0.13[0.09,0.19]^{* * * *}$ \\
\hline Tigrie & $0.45[0.26,0.79]^{* *}$ & $0.34[0.26,0.46]^{* * * *}$ & $0.37[0.29,0.47]^{* * * *}$ \\
\hline Others & $0.90[0.60,1.29]$ & $0.57[0.47,0.68]^{* * * *}$ & $0.62[0.53,0.73]^{* * * *}$ \\
\hline \multicolumn{4}{|c|}{ Knowledge of contraceptive method ( $R C=$ Knows no method) } \\
\hline Knows at least one method & $1.04[0.36,3.04]$ & $1.78[1.21,2.62]^{* *}$ & $1.82[1.25,2.65]^{* *}$ \\
\hline \multicolumn{4}{|l|}{ Contraceptive use $(R C=Y e s)$} \\
\hline No & $0.60[0.45,0.80]^{* *}$ & $0.66[0.57,0.78]^{* * * *}$ & $0.64[0.56,0.73]^{* * * *}$ \\
\hline \multicolumn{4}{|c|}{ Media exposure ( $R C=$ Inadequate $)$} \\
\hline Adequate & $1.16[0.81,1.65]$ & $0.99[0.85,1.15]$ & $1.01[0.88,1.16]$ \\
\hline \multicolumn{4}{|c|}{ Decision-making on own healthcare ( $R C=$ Respondent alone) } \\
\hline Joint decision & $0.81[0.59,1.12]$ & $0.72[0.59,0.87]^{* *}$ & $0.74[0.62,0.88]^{* * * *}$ \\
\hline Husband or someone else & $0.75[0.48,1.18]$ & $0.81[0.66,1.00]$ & $0.83[0.68,1.00]$ \\
\hline \multicolumn{4}{|l|}{ History of abortion $(R C=Y e s)$} \\
\hline No & $0.72[0.46,1.14]$ & $1.00[0.81,1.24]$ & $0.94[0.78,1.14]$ \\
\hline
\end{tabular}

$\mathrm{AOR}=$ adjusted odds ratio, $\mathrm{RC}=$ reference category, ${ }^{*} \mathrm{p}<0.05,{ }^{* *} \mathrm{p}<0.01,{ }^{* * *} \mathrm{p}<0.001,{ }^{* * * *} \mathrm{p}<0.0001$. 
less than the rates for Uganda (43\%) [5] and neighbouring Kenya (44\%); but greater than the rates in Tanzania (21\%) and almost the same as that of Zimbabwe (33\%).

Unintended childbirth rates were highest among women of rich wealth quintile, aged 35-49, never-in-union/married, with $6+$ parity, $7+$ household size, and with primary education. These findings both conflict with and support previous study results. Some indicate that unintended child birth is higher among teenage mothers and nevermarried women [17-19], poor wealth quintile and uneducated women [6,18,20-22]; while others support that women in higher wealth quintile [19] and older women $[22,23]$ had higher odds of unintended childbirths or pregnancies. However, women with secondary and above education were less likely to experience unintended childbirth. This is consistent with results from Bangladesh, Morocco, Colombia and Peru where education showed inverse relation with unintended childbirth $[18,19]$.

Unlike many previous findings whereby wealth quintile and educational status associate with unintended childbirth in the same direction [6,18,20-22], our finding shows a contradicting result in that women of higher wealth quintile households experienced more unintended childbirths while this was true for less educated women. It is worth mentioning here that most of the variables used in the construction of the wealth index in EDHS are characteristics of the urban residents than rural ones. Our analysis shows that $87.5 \%$ of the study population in the highest wealth quintiles were urban residents; and unintended childbirths were more prevalent among urban residents than rural ones. Besides, in EDHS educational status was not used in the construction of wealth index. Consequently, the wealth index in EDHS might not be a good proxy reflection of the socioeconomic status of households at national level. Hence, the relationship between wealth quintile and unintended childbirth needs careful interpretation in relation to research findings from different setups or countries.

In this study, place of residence did not strongly associate with unintended childbirth though urban women reported more unintended last births which is in line with research results from India and Bangladesh $[21,23]$. The high likelihood of unintended pregnancies among urban women however is contrary to the fact that they have relatively more decision-making power on contraceptive use [24] and higher contraceptive coverage [11] than their rural counterparts. This is also contrary to other studies on the correlates of unintended pregnancy or childbirth [6].

Similar to previous studies from Uganda and Tanzania $[6,18]$, a study from Eastern Ethiopia indicates that young and unmarried or formerly married women were at higher risk of experiencing unintended pregnancy [15]. The Ethiopia DHS reports and other institutional and community-based research indicate that despite the encouraging or high level of awareness of modern contraceptives [24-27] young people have limited access to quality sexual and reproductive health or family planning services $[11,25,28]$. Another institution-based study indicates that the level of awareness of sexual and reproductive health rights is very low among University students in Ethiopia [29]. In 2011, only 5\% of young women aged 15-19 used modern contraceptive methods, the lowest among all the reproductive age groups [11]. Similar to another study to a specific locality in Ethiopia, this study found that high parity is significantly associated with higher prevalence of unintended childbirth.

Interestingly too, ethnicity had statistically significant effect on unintended childbirth. In Ethiopia, being Afar, Amhara, Somali, or Tigraway was associated with a lower likelihood of experiencing unintended childbirth compared to being an Oromo. Oromos constitute the biggest ethnic group in Ethiopia. The Oromos as a whole have continued to experience modest declines in fertility in the recent past, but it has been increasing for Afars and Somalis. Somali and Afar have the lowest proportion of women and men with desire to limit childbearing and have the highest total wanted fertility rate in Ethiopia compared to the Oromos. Somali and Afar regions have the poorest exposure to family planning related media and have the lowest contraceptive utilization rate in Ethiopia at $4 \%$ and $9 \%$ respectively, versus $25 \%$ for Oromiya region. The later has also the highest percentage of unmet need for family planning (30\%) [11,28,30].

In the current study, Muslim women had lower odds of having unintended childbirth compared to Orthodox Christians. This might be attributed to the tendency of Muslims to have higher fertility compared Christians. Evidence shows that Muslims have the highest fertility in the regions of Ethiopia with equal Muslim and Christian populations (Oromia and Benishangul-Gumuz), but the lowest among Muslim minority regions [31]. Another EDHS data in-depth analysis shows that Muslim women show better decision making power on their own health care as compared to other religious groups [32].

In interpreting this study's findings, it is advisable to consider some of the limitations of the study. The crosssectional nature of the data does not allow for causal inferences about the relationship between unintended pregnancies or childbirth, and the socioeconomic and demographic correlates. It is important to keep in mind that the analyzed data includes only last births; but possible repeated unwanted pregnancies, those which might have ended in miscarriage, abortion and in some cases turned out to be wanted due to change of mind of the mother or the couple are not measured in this study. As indicated elsewhere, women are more likely to report a current pregnancy rather than a birth that occurred in the past as unintended or 
unwanted due to difficulty in recall [13]. Women who might have died of the unwanted pregnancy are not also part of the data set. Hence, the current analyses might have underestimated the level of unintended childbirth in Ethiopia. Besides, the categories of mistimed and unwanted births were combined as unintended though they have different concepts. This is common practice in the literature $[16,18]$.

\section{Conclusion}

The study found a relatively high prevalence of unintended pregnancy or childbirth in Ethiopia. The burden of unintended childbirth in Ethiopia falls more heavily on young, unmarried, multipara, and ethnic majority women and those with primary or no education. Knowledge on any method of family planning and use of contraceptives is also an important factor that is directly related to unintended birth. Exposure to media and wealth status didn't show any significant net effect on unintended childbirth.

The study suggests an association between socioeconomic and demographic factors and the risk of unintended childbirth. The high proportion of mistimed births in this study is a reflection of the need for spacing, and the relatively lower proportion of unintended births reflects the need for reducing ideal family size and limiting fertility in Ethiopia. A recent study conducted in northwest Ethiopia showed that the majority of contraceptive users prefer child spacing to limiting [27], which supports findings from other parts of Africa [33]. The findings are crucial and imply the need for programs and strategies to strengthen and improve access to contraceptive services, raise educational levels, and related information and communication to bring attitudinal change among the affected women and lower the desire for additional children. Special emphasis should be given to uneducated, unmarried, younger, and multipara women.

Further quantitative and qualitative research on the consequences of unintended (mistimed and unwanted) pregnancy and child birth related to prenatal and perinatal outcomes including abortion, physical and mental health are vital to document process of change in the problem overtime. It would also be advisable to include questions in DHS regarding repeated unwanted pregnancies, outcomes of unwanted pregnancy to measure miscarriage, abortion, live births, neonatal mortalities, its consequences on the physical and psychosocial health of the woman and others. Moreover, qualitative research is needed to understand the underlying reasons for the continuity of the above factors.

\section{Competing interests}

All authors declare that they have no competing interests.
Authors' contributions

YT conceived of the research topic and performed the statistical analysis and drafted the write up. BA and CT were fully involved in its write up and interpretation. All the authors have read and approved the final manuscript.

\section{Acknowledgements}

We are grateful to the Central Statistical Agency of Ethiopia and ICF International for making the DHS data available.

\section{Author details}

${ }^{1}$ World Health Organization, Juba, Republic of South Sudan. ${ }^{2}$ BZY Research Consult, Addis Ababa, Ethiopia. ${ }^{3}$ Department of Global Health, Milken Institute of Public Health, George Washington University, Washington, DC, USA.

Received: 3 March 2014 Accepted: 16 September 2014

Published: 18 September 2014

\section{References}

1. World Health Organization: Unsafe Abortion: Global and Regional Estimates of the Incidence of Unsafe Abortion and Associated Mortality in 2008. 6th edition. Geneva: World Health Organization; 2011.

2. World Health Organization: Unsafe abortion incidence and mortality Global and regional levels in 2008 and trends during 1990 -2008, Information sheet. Geneva: World Health Organization; 2012.

3. World Health Organization: Unsafe Abortion: Global and Regional Estimates of the Incidence of Unsafe Abortion and Associated Mortality in 2003. 5th edition. Geneva: WHO; 2007.

4. Frost JJ, Darroch JE, Remez L: Improving contraceptive use in the United States. In Brief. No. 1. New York: Guttmacher Institute; 2008.

5. Singh S, Sedgh G, Hussain R: Unintended Pregnancy: Worldwide Levels, Trends, and Outcomes. Stud Fam Plan 2010, 41(4):241-250.

6. Hussain R: Unintended pregnancy and abortion in Uganda. In Brief. No 2. New York: Guttmacher Institute; 2013.

7. Gebreselassie H, Fetters T, Singh S, Abdella A, Gebrehiwot Y, Tesfaye S, Takele G, Kumbi S: Caring for women with abortion complications in Ethiopia: national estimates and future implications. Int Perspect Sex Reprod Health 2010, 36(1):6-15.

8. Federal Ministry of Health: Technical and Procedural Guidelines for Safe Abortion Services in Ethiopia. Addis Ababa: Federal Ministry of Health of Ethiopia; 2006.

9. Ethiopia: National Population Policy of Ethiopia. Addis Ababa: Office of the Prime Minister; 1993

10. Nations U: Report of the International Conference on Population and Development: Cairo 5-13 September 1994. New York: United Nations; 1995.

11. Central Statistical Agency [Ethiopia] and ICF International: Ethiopia Demographic and Health Survey 2011. Addis Ababa, Ethiopia and Calverton, Maryland, USA: Central Statistical Agency and ICF International; 2012.

12. Ikamari L, Izugbara C, Ochako R: Prevalence and determinants of unintended pregnancy among women in Nairobi, Kenya. BMC Pregnancy Childbirth 2013, 13:69.

13. Kassa N, Berhane $Y$, Worku A: Predictors of unintended pregnancy in Kersa, Eastern Ethiopia, 2010. Reprod Health 2012, 9:1.

14. Singh S, Sedgh G, Hussain R: The estimated incidence of induced abortion in Ethiopia. Int Perspect Sex Reprod Health 2010, 36(1):16-25.

15. Solomon W, Mesganaw F: Unintended pregnancy and induced abortion in a town with accessible family planning services: The case of Harar in Eastern Ethiopia. Ethiopian Journal of Health Redevelopment 2006, 20(2):79-83.

16. Bradley SEK, Croft TN, Rutstein SO: The Impact of Contraceptive Failure on Unintended Births and Induced Abortions: Estimates and Strategies for Reduction, DHS Analytical Studies No. 22. Maryland: ICF Inc.; 2011.

17. Exavery A, Kante AM, Hingora A, Mbaruku G, Pemba S, Phillips JF: How mistimed and unwanted pregnancies affect timing of antenatal care initiation in three districts in Tanzania. BMC Pregnancy Childbirth 2013, 13:35.

18. Calvert C, Baisley K, Doyle AM, Maganja K, Changalucha J, Watson-Jones D, Hayes RJ, Ross DA: Risk factors for unplanned pregnancy among young women in Tanzania. J Fam Plann Reprod Health Care 2013, 0:1-12. doi:10.1136/jfprhc-2012-100389 
19. Adetunji JA: Unintended childbearing in developing countries: levels, trends and determinants, Demographic and Health Surveys Analytical reports No. 8. Maryland: Macro International Inc.; 1998

20. LeMier M: Unintended pregnancy. Washington State Department of Health: Health of Washington State; 2013.

21. Dixit $P$, Ram F, Dwivedi LK: Determinants of unwanted pregnancies in India using matched case-control designs. BMC Pregnancy Childbirth 2012, 12:84.

22. Yuossef RM, Moubarak II, Gaffar YA, Atta HY: Correlates of unintended pregnancy in Beheira governorate, Egypt. East Mediterr Health J 2002, 8(4/5):521-526.

23. Sarkar P: Unintended pregnancies in Bangladesh: Levels and correlates. J Mod Math Stat 2009, 3(4):78-81.

24. Bogale B, Wondafrash M, Tilahun T, Girma E: Married women's decision making power on modern contraceptive use in urban and rural southern Ethiopia. BioMed Central Public Health 2011, 11:342.

25. Kibret M: Reproductive health knowledge, attitude and practice among high school students in Bahir Dar, Ethiopia. Afr J Reprod Health 2003, 7(2):39-45.

26. Tegegn A, Yazachew M, Gelaw Y: Reproductive Health Knowledge and Attitude among Adolescents: A community based study in Jimma Town, Southwest Ethiopia. Ethiop J Health Dev 2008, 22(3):243-251.

27. Weldegerima B, Denekew A: Women's knowledge, preferences, and practices of modern contraceptive methods in Woreta, Ethiopia. Res Soc Adm Pharm 2008, 4(3):302-307.

28. Central Statistical Agency [Ethiopia] and ORC Macro: Ethiopia Demographic and Health Survey 2005. Addis Ababa and Maryland: Central Statistical Agency [Ethiopia] and ORC Macro; 2006.

29. Adinew YM, Worku AG, Mengesha ZB: Knowledge of reproductive and sexual rights among University students in Ethiopia: institution-based cross-sectional. BMC International Health and Human Rights 2013, 13:12.

30. Central Statistical Agency [Ethiopia] and ORC Macro: Ethiopia Demographic and Health Survey 2000. Addis Ababa and Maryland: Central Statistical Agency [Ethiopia] and ORC Macro; 2001.

31. Teller C, Gebreselassie T: Religious, Ethnic, and Regional Factors of High Fertility in Ethiopia. 2009, http://www.prb.org/Publications/Articles/2009/ ethiopiamuslimdemographics.aspx.

32. Ethiopian society of Population Studies: Gender inequality and women's empowerment: In-depth analysis of the Ethiopian Demographic and Health Survey 2005. Addis Ababa: United Nations Population Fund (UNFPA); 2008.

33. Creanga AA, Gillespie D, Karklins S, Tsui AO: Low use of contraception among poor women in Africa: an equity issue. Bull World Health Organ 2011, 89(4):258-266.

doi:10.1186/1471-2393-14-326

Cite this article as: Tebekaw et al.: Prevalence and determinants of unintended childbirth in Ethiopia. BMC Pregnancy and Childbirth 2014 14:326.

\section{Submit your next manuscript to BioMed Central and take full advantage of:}

- Convenient online submission

- Thorough peer review

- No space constraints or color figure charges

- Immediate publication on acceptance

- Inclusion in PubMed, CAS, Scopus and Google Scholar

- Research which is freely available for redistribution 